Canadian Journal of Fisheries and Aquatic Sciences

Canadian Science Publishing Journal canadien des sciences halieutiques et aquatiques

\title{
Impact of vessel traffic on the home ranges and movement of Shorthorn Sculpin (Myoxocephalus scorpius) in the nearshore environment of the high Arctic
}

\begin{tabular}{|c|c|}
\hline Journal: & Canadian Journal of Fisheries and Aquatic Sciences \\
\hline Manuscript ID & cjfas-2017-0418.R1 \\
\hline Manuscript Type: & Article \\
\hline Date Submitted by the Author: & 02-Mar-2018 \\
\hline Complete List of Authors: & $\begin{array}{l}\text { Ivanova, Silviya; University of Windsor, Great Lakes Institue of } \\
\text { Environmental Research } \\
\text { Kessel, Steven; University of Windsor, Great Lakes Institue of } \\
\text { Environmental Research; John G. Shedd Aquarium, Daniel P. Herther } \\
\text { Center for Conservation and Research } \\
\text { Landry, Justin; University of Windsor, Great Lakes Institute for } \\
\text { Environmental Research } \\
\text { O'Neill, Caitlin; University of British Columbia Faculty of Graduate Studies } \\
\text { McLean, Montana; Dalhousie University } \\
\text { Espinoza, Mario; Universidad de Costa Rica, Centro de Investigación en } \\
\text { Ciencias del Mar y Limnología \& Escuela de Biología } \\
\text { Vagle, Svein; Department of Fisheries and Oceans, OSD } \\
\text { Hussey, Nigel; University of Windsor, GLIER } \\
\text { Fisk, Aaron; University of Windsor, Great Lakes Institute for Environmental } \\
\text { Research }\end{array}$ \\
\hline $\begin{array}{r}\text { Is the invited manuscript for } \\
\text { consideration in a Special } \\
\text { Issue? : }\end{array}$ & Oceans Tracking Network \\
\hline Keyword: & $\begin{array}{l}\text { Shorthorn Sculpin, acoustic telemetry, Arctic, movement ecology, } \\
\text { anthropogenic disturbance }\end{array}$ \\
\hline
\end{tabular}


Impact of vessel traffic on the home ranges and movement of Shorthorn Sculpin and Aaron T. Fisk ${ }^{1}$

$8{ }^{1}$ Great Lakes Institute for Environmental Research, University of Windsor, 401 Sunset

9 Ave, Windsor, ON, N9B 3P4, Canada.

$10{ }^{2}$ University of Victoria, Victoria, British Columbia, V8P 5C2, Canada.

$11{ }^{3}$ Biology Department, Dalhousie University, Halifax, Nova Scotia, B3H 4R2, Canada.

$12{ }^{4}$ Centro de Investigación en Ciencias del Mar y Limnología \& Escuela de Biología,

13 Universidad de Costa Rica, Costa Rica.

$14{ }^{5}$ Current address: Daniel P. Haerther Center for Conservation and Research, John G.

15 Shedd Aquarium, 1200 South Lake Shore Drive, Chicago, IL 60605, USA.

$16{ }^{6}$ Institute of Ocean Sciences, Fisheries and Oceans Canada

$17{ }^{7}$ Current address: Biological Sciences, University of Windsor, 401 Sunset Avenue,

18 Windsor, ON, N9B 3P4, Canada.

19

20

21 * Corresponding author: Silviya V. Ivanova, University of Windsor, 401 Sunset Ave,

22 Windsor, ON, N9B 3P4. Email: ivanovas@uwindsor.ca 


\section{Abstract:}

24 Sea ice reduction in the Arctic is allowing for increased vessel traffic and activity. Vessel

25 noise is a known anthropogenic disturbance but its effects on Arctic fish are largely

26 unknown. Using acoustic telemetry - Vemco ${ }^{\circledR}$ Positioning System (VPS) - we quantified

27 home ranges and fine-scale movement types (MT) of Shorthorn Sculpin (Myoxocephalus

28 scorpius), a common benthic Arctic fish, in response to vessels and environmental drivers

29 during open water over three years (2012-2014). Low overlap of core home ranges (50\%)

30 for all years and a change of overall MT proportions (significant in 2012 only) were

31 observed when vessels were present compared to absent. However, changes in MTs

32 associated with vessel presence were not consistent between years. Photoperiod was the

33 only environmental driver that influenced $\left(\mathrm{R}^{2}=0.32\right) \mathrm{MTs}$ of sculpin. This is the first

34 study of vessel impacts on arctic fish using acoustic telemetry and demonstrates that

35 individuals alter their behavior and home ranges when vessels are present. Given

36 increasing vessel traffic in the Arctic, additional study on the impact of vessels on these

37 ecosystems is warranted.

38

39 Keywords: Shorthorn Sculpin, acoustic telemetry, Arctic, benthic fish, movement

40 ecology, anthropogenic disturbance. 


\section{Introduction}

42 Ships and boats, hereafter vessels, produce noises that fall within the same

43 frequency range as fish hearing and communication (Slabbekoorn et al. 2010), and have

44 been documented to impact fish behavior, movements and distributions (Holles et al.

45 2013; Vabø et al. 2002), and are known to cause stress and mortality by predation

46 (Wysocki et al. 2006; Simpson et al. 2016) in temperate and tropical ecosystems. Vessels

47 can also increase water turbidity, which can alter vegetation and substrate that are critical

48 habitat to fish for refuge and spawning (Eriksson et al. 2004; Sandström et al. 2005).

49 Anthropogenic disturbance due to vessel activity is a relatively new issue in the Arctic

50 region, and while attention has been focused on its impact on marine mammals (Nowacek

51 et al. 2007) such studies on fish are lacking. This has been partly due to the difficulty of

52 accessing the Arctic but also due to lack of suitable technologies.

53 Recent technological advancements are allowing for novel in-situ scientific

54 observations of individual fish in a wide range of environments through the application of

55 acoustic telemetry (Hussey et al. 2015), providing an excellent tool to assess the impacts

56 of vessels on arctic fish behavior. Acoustic telemetry utilizes either manual tracking or

57 fixed stations, and the latter has the advantage of tracking animals remotely over long

58 periods of time to provide high resolution movement data (Cooke et al. 2013; Hussey et

59 al. 2015; Kessel et al. 2015). Organisms are usually tagged internally and released, with

60 the tag emitting a unique signal every few minutes, which, when in range, is logged by

61 fixed listening stations, called receivers. When receiver arrays are arranged strategically

62 to allow tag signals to be detected simultaneously on three or more receivers, continuous

63 locations of individual fish can be quantified. Such high-resolution positional data has 
64 allowed quantification of fine scale movement behaviors of fish (McLean et al. 2014;

65 Landry et al. see this issue), and extraction of home ranges and spatial use patterns of

66 different species (Hussey et al. 2015). In addition, telemetry can be used to study the

67 effects of anthropogenic disturbance on fish in-situ. For example, Vaudo and Lowe

68 (2006) showed that coastal development influenced the movements of stingrays and

69 Russell et al. (1998) demonstrated that salmonids change their movement patterns when

70 estuarine barrages are present.

71 Receding of sea ice in the Arctic (Richardson et al. 2016; Comiso et al. 2008) has

72 opened up the Northwest Passage to exploration, ship traffic and increased development

73 and exploitation of natural resources (US Energy Information Administration 2012;

74 Cressey 2011). In addition to the greater vessel traffic in the Arctic related to growing

75 fisheries, oil and mining industries, the Northwest Passage is also a preferred route

76 between North America, Europe and Asia for shipping companies (Standing Senate

77 Committee on Fisheries and Oceans 2009), and of increasing interest to tourists and

78 cruise-liners (Dawson et al. 2014). Thus, anthropogenic disturbance due to vessel traffic

79 in the Arctic is growing, providing an excellent opportunity to understand the impact of

80 vessel activity on fish behavior in a relatively non-impacted region, but also requiring

81 study to guide management and conservation of this sensitive ecosystem.

82 The Arctic Ocean is a low species richness ecosystem (Kortsch et al. 2015) that is

83 experiencing multiple stressors driven directly and indirectly by climate change,

84 including decreasing ice cover, expansion of temperate fish species into the Arctic

85 (Kortsch et al. 2015), and increasing vessel activity (Cressey 2011). Thus, due to its

86 lower functional redundancy in species, the Arctic would be impacted more by these 
87 stressors than temperate and tropical ecosystems. Given this, information on fish

88 movement behavior and spatial/habitat utilization is necessary for conservation initiatives

89 and management, especially with new evidence of the large scale movement of arctic

90 organisms (Heide-Jørgensen et al. 2003; Hauser et al. 2014), including forage fish

91 (Kessel et al. 2017). Without an understanding of how vessel activity in the Arctic affects

92 the movement and behavior of aquatic species, it will be difficult to manage this

93 ecosystem in a sustainable manner.

94 Shorthorn Sculpin (Myoxocephalus scorpius) is a benthic fish found in high

95 abundance throughout the Arctic (Seth et al. 2013), with a relatively wide range of

96 temperature tolerance (Seth et al. 2013; Grans et al. 2013). Seth et al. (2013) suggested

97 these sculpin are a "sit-and-wait predator", and use cover when under predation threat.

98 Sculpin feed on invertebrates and fish, are known for cannibalism (Landry JJ, Fisk, AT,

99 Yurkowski, DJ, Hussey, NE, Dick, T, Crawford, RE, and Kessel ST. In press), and

100 although not considered a preferred prey item, have a wide range of predators, from

101 seabirds, such as the Black Guillemot (Cepphus grylle) (Divoky \& Tremblay 2013), to

102 marine mammals, such as beluga whales (Delphinapterus leucas) (Breton-Honeyman et

103 al. 2016) and seals (Lowry et al. 1980), to Greenland sharks (Somniosus microcephalus)

104 (Fisk et al. 2002). Shorthorn Sculpin represent an indicator species for Arctic marine

105 ecosystems in part due to their limited long-distance movements (Dick et al. 2009) and as

106 such, a baseline understanding of their ecology in the Arctic is important to predict

107 anthropogenic effects in the future.

108 In this study, we used fixed station acoustic telemetry, specifically VPS, to track

109 and record high-resolution Shorthorn Sculpin movements over a period of three years 
110 (2012 - 2015) in Resolute Bay, Nunavut, a small bay in the high Canadian Arctic. Data

111 from the tagged individuals were used to examine the spatial use and fine-scale

112 movements of these benthic fish in relation to vessel activity and the environment during

113 the open water ice-free period of summer and early autumn. We hypothesized that

114 sculpin would exhibit a change in behavior and movement when vessels were moving

115 and present compared to periods when absent, and specifically predicted that: individuals

116 will exhibit lower rates of movement during vessel movement and presence, and, in

117 periods when vessels are present sculpin will reduce their spatial use (home ranges) in the

118 bay.

\section{Methods}

121 Study Site

122 Resolute Bay, Nunavut $\left(74.6773^{\circ} \mathrm{N}\right.$ and $\left.94.8297^{\circ} \mathrm{W}\right)$ is located on the north shore

123 of the Northwest Passage and vessels are common in the bay during open water periods

124 (approx. end of July till end of September), utilizing it as an anchorage area for supplies

125 restocking and passenger exchange. The settlement is to the northeast of the bay, has 243

126 residents (Anon 2013), and contributes nutrients through the sewage outflow. The bay is

127 generally $<20 \mathrm{~m}$ deep, with the head of the bay reaching a depth of $30 \mathrm{~m}$ and a shallow

128 sill reaching $1 \mathrm{~m}$ depth at low tide located at the center of the mouth of the bay (Fig. 1).

129 One small river on the west shore and two streams on the east contribute freshwater

130 input.

131 Fish telemetry 
133 August 2012, 2013 and 2014 with a gill net (30 m length, 2 inch mesh size) set for 6 hrs,

134 in three locations - northeastern, northwestern and southwestern part of the bay. The

135 number of individuals tagged in 2012, 2013 and 2014 were 22, 12, and 26, respectively.

136 Upon capture, total length (L) was measured to the nearest $1 \mathrm{~mm}$ and mass (M) to nearest

$1370.1 \mathrm{~g}$ prior to insertion of acoustic tags. Condition index $(\mathrm{K})$ was calculated using the 138 formula:

140 Vemco ${ }^{\circledR}$ V9 (Halifax, Nova Scotia, Canada, years 2012 and 2013) and Vemco ${ }^{\circledR}$

141 V6 (year 2014) acoustic transmitters, i.e., tags, were used in this study with tag to body

142 weight ratio of $<2 \%$ for all individuals. Following capture, fish were held in $120 \mathrm{~L}$

143 coolers, filled with bay water and water was agitated regularly to maintain oxygen levels

144 prior to tag insertion surgery. An anaesthetic bath of MS222 (1:5 ratio with sea water) for

$1452-5$ min was used for fish sedation. Individuals were placed in a sponge bed for surgery,

146 with gills irrigated continuously with seawater. A ventral incision $(\sim 8 \mathrm{~mm})$ anterior of the

147 pelvic fins was made for tag insertion and closed with three independent sutures (coated

148 Vicryl Ethicon ${ }^{\circledR}$ VCP423, 3-0 FS-2 cutting) each tied with a triple surgeon's knot;

149 procedure duration was 2 to $4 \mathrm{~min}$. A $10 \%$ betadine solution was used for sterilizing all

150 surgical equipment and the incision site. Fish were left to recover in a holding tank with

151 seawater and aeration, and monitored until equilibrium was regained. Individuals were

152 released at the capture location approximately $1 \mathrm{hr}$ after completion of surgery.

153 In 2012 and 2013, a Vemco ${ }^{\circledR}$ VR2W $69 \mathrm{kHz}$ acoustic receiver array, consisting of

15444 units each year, was used to record movements of individual fish, while in 2014 the 
155 array consisted of 28 Vemco ${ }^{\circledR}$ VR2W $180 \mathrm{kHz}$ units (Fig. 2). Each year the array was

156 deployed in the beginning of August and recovered at approximately the same time the

157 following year. Due to considerations for winter ice cover, a minimum deployment depth

158 of $15 \mathrm{~m}$ was used with spacing between individual units from 150 to $300 \mathrm{~m}$. Each unit

159 consisted of a $\sim 40 \mathrm{~kg}$ rock anchor attached via $\sim 2 \mathrm{~m}$ rope to an ORE Port ME acoustic

160 release (manufactured by Edge Tech, USA), the receiver and a subsurface float to

161 maintain the mooring in an upright position. Sync tags were attached to 19 receivers

162 across the array and were used for receiver clock drift correction during the processing of

163 positional data (Espinoza et al. 2011).

164 Presence and movement of ships in Resolute Bay

165 To determine vessel absence, presence and movement times, we used Satellite

166 Automatic Identification System (AIS) archive data from 2012, 2013, and 2014. Data

167 from August and September were used, as these are the months with ship activity in

168 Resolute Bay. A total of 7, 10 and 7 vessels ( $>40$ m length) visited Resolute Bay in 2012,

1692013 and 2014, respectively. All vessels enter and exit the bay using two shipping lanes

170 and the times for entry/exit were extracted from the AIS dataset. These times were cross-

171 referenced with a time-lapse footage set at $10 \mathrm{~s}$ intervals in 2014 from a camera facing

172 the bay (Canon EOS T4, 50mm lens, set in a weather-proof box with constant power

173 supply). From this footage, we determined that passenger and cargo vessels took 10 and

$17430 \mathrm{~min}( \pm 1 \mathrm{~min})$, respectively, to enter the bay, and 15 and $30 \mathrm{~min}( \pm 1 \mathrm{~min})$ to exit.

175 Passenger vessels typically use the western track and cargo vessels utilize the eastern

176 track (see Fig. 1). An additional 5 min were added to the time of anchorage and time

177 prior to departure for statistical analysis to include noise from anchor dropping or pulling, 
178 respectively. Vessel states were defined as follows: vessels absent from the bay (VA);

179 vessels were moving either entering or exiting the bay (VM); and vessels were anchored

180 and thus present in the bay, but not moving (VP).

181 Acoustic telemetry data processing

182 Positional data was generated by processing all raw data through Vemco's VPS

183 analysis. The analysis uses the differences in detection times in milliseconds at three or

184 more time-synchronized receivers to triangulate the position of the signal/individual

185 (Smith 2013). Positional data for $\mathrm{n}=22,14$ (includes 2 IDs from 2012 tagging) and 26

186 individuals in 2012, 2013 and 2014, respectively, was filtered for HPE (horizontal

187 position error, a unitless estimate of the sensitivity of the calculated position (Smith

188 2013)), and any HPE values larger than 37 were removed from further analysis. This

189 value for HPE was chosen based on the average relative to the HPE for the sentinel tags

190 in our VPS as suggested by Smith (2013), resulting in a distance error of $>10 \mathrm{~m}$. In 2014,

191 the total IDs used for further analysis dropped to 12 individuals due to lack of sufficient

192 detections. A total of 20,847, 16,882, and 3,478 detections for 2012, 2013 and 2014,

193 respectively, were included in the final analysis.

194 To generate home ranges and estimate movement behaviors of sculpin

195 adeHabitatHR and adeHabitatLT packages (Calenge 2006) in R (version 0.98 .1103

196 running on Mac OS X 10.9.5), respectively, were used. These metrics were grouped into

197 three vessel variables: 1) vessels absent from the bay (VA), 2) vessels present/anchored

198 in the bay (VP), and 3) vessels moving, either entering or exiting the bay (VM). During

199 VP, vessel generators were running to produce and supply power, and small boats

200 transported passengers and/or goods to the shore and back, adding more noise to the 
201 background. During VM additional noise stems mainly from the vessel's propellers, the 202 vessel moving through the water, and anchor dropping or pulling. Small boat noises, such 203 as these produced by local fisherman's boats and recreational yachts $<40 \mathrm{~m}$ in length 204 occurred during VA, VP and VM, but were not considered in the analysis because the 205 duration of these boats' activities within the bay was fairly short (2-3 minutes) and 206 occurred sporadically during each vessel state. In comparison, boats/servicing tenders of 207 ships during VP moved consistently from the vessel to the shore.

208 Sculpin's core and general home ranges were established using Kernel utilization 209 distributions (KUD) at 50\% and 95\%, while Minimum Convex Polygon (MCP) was used 210 to determine the extended home range area. The data were separated by vessel variable

211 (VA, VP and VM) and home range analysis was performed for all individuals that had $\geq 5$

212 detections (Table 2). Home ranges for each individual and variable were mapped

213 separately and sizes calculated in hectares. Using CalcHR.R and Indices.txt (Fieberg \&

214 Kochanny 2005) we performed an overlap estimation for 50\% and 95\% KUD for VP, VA

215 and VM by calculating the Hurlbert Index of overlap. To examine the differences in

216 individual MCP area sizes between VA and VP, a Kruskal-Wallis rank sum test was 217 undertaken.

218 Sculpin movement behaviors were quantified using trajectory bursts - discrete 219 segments of successive VPS positions (Turchin 1998). Bursts were extracted from each 220 individual's trajectory (a collection of VPS positions forming a continuous curve of that 221 individual's movements (Calenge et al. 2009)) based on time and date of detection with 222 cut off between bursts of $>30$ min between consecutive positions, i.e., no detections of 223 the individual. Only bursts with a minimum of 5 consecutive VPS positions were 
224 considered. This allowed for the elimination of prolonged/excessive periods between

225 detections/positions of individual fish, providing continuous high-resolution data to

226 identify distinct movement behaviors. We clustered the bursts using a diagonal, varying

227 volume and shape (VVI) model with 3 components as suggested by the Mclust function

228 (Fraley \& Raftery 1999) in R. Descriptive parameters with correlations greater than 0.45

229 were removed. We used the following descriptive parameters to define the bursts'

230 movement types (MT): 1) distance between successive relocations; (2) rate of movement

231 (ROM; $\mathrm{m} \mathrm{s}^{-1}$ ); (3) turning angle, which measures the change in direction between

232 relocations; (4) a linearity ratio, where 1 denotes a straight path and 0 a less linear path

233 (Heupel et al. 2012); (5) total distance travelled in a burst; (6) bearing; (7) depth; and (8)

234 acceleration (7 and 8 were only available in 2012 and 2013).

235 Based on the time and date of their occurrence, identified burst MTs were

236 assigned to the three vessel variables (VA, VP and VM), and individual and mean

237 proportions of each were calculated (Table 3). A chi-squared test was performed for the

238 mean proportions of VP and VM using VA as the expected value to determine overall

239 differences in MT proportions between vessel variables. To determine the actual

240 differences between identified MTs for VA, VP and VM, we compared individual

241 proportion values using Kruskal-Wallis rank sum test and T-test as appropriate based on

242 our results from a Shapiro-Wilk normality test.

243 Environmental variables processing

244 Hourly-averaged salinity (PSU), water temperature $\left({ }^{\circ} \mathrm{C}\right)$, and dissolved oxygen

245 saturation (\%) were collected using a Satlantic STOR-X submersible data logger with a

246 Seabird 37-SIP microCAT C-T recorder, sampling for $30 \mathrm{~s}$ every hour at resolutions of 1, 
247 1, and $5 \mathrm{~s}$, respectively. The instruments were deployed and retrieved in August of each 248 year, and were located approximately $0.5 \mathrm{~m}$ above the seafloor, in $33 \mathrm{~m}$ of water in the

249 depression at the head of the bay $\left(74.68549^{\circ} \mathrm{N} 94.86194^{\circ} \mathrm{W}\right)$. Daily average wind speeds

250 and air temperatures were obtained from the Environment and Climate Change Canada

251 online archives (Weather Canada 2015). Photoperiod (h) was downloaded from the time

252 and date online archives (Steffen Thorsen 2014). A general linear mixed model was used

253 to assess the influence of environmental variables on MTs. Variables with correlation

$254>30$ were removed from analysis for all years. We used vessel activity, photoperiod,

255 dissolved oxygen and wind speed as fixed effects in 2012. Similarly, for 2013 plus

256 salinity; however, in 2014 only vessel activity, photoperiod and dissolved oxygen were

257 used. Fish ID was added as a random effect for all years. Based on the model, variables

258 that showed significance were examined individually to establish the strength of the

259 relationships using linear regression.

\section{Results}

262 Sculpin body sizes

263 There was no significant difference in total length of tagged sculpin between 2012

264 and 2013 ( $\mathrm{p}=0.57$; t-test with equal variances), however, 2014 fish were significantly

265 smaller than both 2012 and 2013 (both $\mathrm{p}<0.01$; t-test with equal variances) (Table 1).

266 Condition index calculations showed no significant differences in individual condition

267 among years (all $\mathrm{p}>0.05$, t-test).

268 Movement types 
For 2012, MTs were explained by mean rate of movement (ROM), linearity,

270 mean depth, and standard deviation (SD) of turn angle and acceleration (Kruskal-Wallis

271 rank sum test; Fig. 3). Higher ROM, acceleration and depth, and more linear trajectory

272 with lower turning angles characterized MT 2 and distinguished it from MTs 1 and 3. MT

2731 had the lowest rate of movement and acceleration, and somewhat lower linearity than

274 MT 3. Medium ROM, linearity and acceleration defined MT 3. In 2013, descriptive

275 parameters that significantly influenced MTs were mean ROM, sum of distance, SD of

276 turn angle and acceleration (Kruskal-Wallis rank sum test; Fig. 3). Similarly to 2012,

277 highest ROM, sum of distance and acceleration distinguished MT 2 from the rest. MT 1

278 had the lowest acceleration and sum of distance values, while MT 3 had medium values.

279 For 2014, mean ROM, linearity, sum of distance and SD of turn angle were significant (p

$280<0.001$ for all, Kruskal-Wallis rank sum test; Fig. 3). Here too, MT 2 had the highest

281 ROM and sum of distance, and MT 1 had the lowest of these values, although both had

282 very similar linearity. MT 3 had medium values for ROM and sum of distance, but the

283 lowest linearity.

284 Based on these variables for all three years, MT 1 was identified as behavior

285 typical of fish that are feeding/hiding, MT 2 as typical of in-transit movement, and MT 3

286 as typical of foraging behavior (Fig. 4).

287 Influence of vessels on movement types

288 In 2012 and 2014, there were no significant differences in overall MT proportions

289 between vessel variables (chi-squared, $p>0.05$, Fig. 5). However, in 2013 a change in

290 overall MT proportions was observed for VA compared to VP (chi-squared $=7.46, \mathrm{p}=$

291 0.024), but not for VA and VM (chi-squared $=0.745, p=0.69$ ). Examining each MT 
292 separately between vessel variables in 2012 and 2013, we found MT 1, associated with

293 feeding/hiding, decreased significantly when vessels were moving in the bay in 2012

294 compared to periods when vessels were absent ( $\mathrm{p}=0.034$, Kruskal-Wallis rank sum test;

295 Fig. 5), while in-transit movement (MT 2) in 2013 decreased significantly when vessels

296 were present (VP) in comparison to when vessels were absent ( $p=0.012$, Kruskal-Wallis

297 rank sum test; Fig. 5).

298 Vessel movements occur over 10 to 30 minute periods and identified MTs often

299 spanned vessels movement, presence and/ or absence periods. This confounded our

300 ability to tease apart any influence of VM on MTs. Thus, significant differences in MTs

301 during VM periods are reported above but excluded from further analysis and discussion.

302 Influence of environment on fish behavior

303 A general linear mixed model analysis for environmental variables revealed

304 photoperiod and vessel activity in 2012 ( $p<0.001$ for both) significantly influenced the

305 proportions of MTs. However, linear regressions of photoperiod with individual MTs had

306 low R-squared values (R-squared $<0.1$ for all). In 2013, vessels, photoperiod and wind

307 speed were significant for the model ( $\mathrm{p}<0.01$ for all), however only photoperiod

308 influenced MT 2 in the linear regression (R-squared =0.32; Fig. 6). MT 2 (in-transit

309 movement) increased in frequency with decreasing daylight, while MT 1 and MT 3

310 (feeding/hiding \& foraging movement, respectively) showed a slight decrease. In 2014,

311 vessels, photoperiod and hourly dissolved oxygen significantly influenced sculpin's MTs

312 in the model ( $\mathrm{p}<0.05$ for all); however, linear regression R-squared values were low (R-

313 squared $<0.03$ for all variables).

314 Home Ranges 
315 Home ranges during vessel movement $(\mathrm{VM})$ periods are reported for each year

316 but excluded from further analysis and discussion due to bias resulting from shorter

317 periods of time over which detections during VM were collected.

318 In 2012, MCP area for VP and VM were lower when compared to VA periods

319 (VA; $p$-value $=0.002$, and $<0.001$, respectively; Kruskal-Wallis rank sum test; Fig. 7 and

320 8). Hurlbert overlap test had a mean index of 0.073 and 0.375 for $50 \%$ and $95 \%$ KUD,

321 respectively, between VA and VP.

322 In 2013, MCP decreased significantly during VP and VM $(p=0.028$ and 0.01 ,

323 respectively; Kruskal-Wallis rank sum test; Fig. 7 and 8). Area for 50\% and 95\% KUD

324 also decreased significantly for VM as compared to VA ( $p<0.02$ for both). The mean

325 overlap was 0.114 and 0.325 for 50\% and 95\% KUD, respectively, for VA vs VP.

326 In 2014, no significant differences were found in any of the area sizes (all $p$ >

327 0.15, Fig. 8); however, it should be noted that sample size was low (VA $n=4$, VP $n=4$,

328 and VM $\mathrm{n}=2$ ). The overlaps between VA and VP for 50\% and 95\% KUD were 0.248 and

3290.149 , respectively (Kruskal-Wallis rank sum test). For VA vs VM test was not

330 performed due to the low sample size. The Hurlbert overlap test $(n=4)$ between VA and

331 VP revealed a low overlap with mean index of 0.013 and 0.063 for $50 \%$ and $95 \%$ KUD,

332 respectively.

\section{Discussion}

335 In all three years of this study, we identified three general movement types for

336 Shorthorn Sculpin in Resolute Bay, Nunavut using VPS acoustic telemetry -

337 feeding/hiding (MT 1), in-transit (MT 2) and foraging (MT 3). In-transit behaviour 
338 decreased with vessel presence in 2013, but not in other years. In all three years - 2012,

3392013 and 2014 - the extent of spatial use by sculpin was smaller for all individuals when

340 vessels were present, and core home ranges had low overlap between times of vessel

341 absence and presence. This study demonstrates that the presence of large vessels can

342 impact benthic fish habitat use in nearshore Arctic environments, with implications for

343 management and conservation in the light of expanding vessel traffic in these sensitive

344 ecosystems.

345 During 2012 and 2013, in periods with no vessels, feeding/hiding behavior (MT1)

346 was the most frequent movement behavior for Shorthorn Sculpin, followed by foraging

347 (MT3) and in-transit movement (MT2). Kasumyan (1999) looked at five different species

348 of sturgeon and identified each to have a slow and twisting movement trajectory in

349 response to prey odors in holding tanks, similar to MT 1 in this study. Sturgeon are also

350 benthic fish, although they are not considered a sit-and-wait predator, and instead search

351 for benthic food using barbels. McLean et al. (2014), using VPS, attributed to feeding

352 similar behavior adopted by Atlantic Sturgeon (Acipenser oxyrinchus) when in prey

353 patches. Similar movement trajectories have been observed for terrestrial species, such as

354 the Baltimore Checkerspot butterfly (Euphydras phaeton), which had shortest movement

355 lengths and large turning angles in habitats where food was abundant (Brown et al. 2017).

356 As Shorthorn Sculpin is thought to be a sit-and-wait predator, the very low rate of

357 movement for MT 1 indicates feeding associated behavior. However, it could indicate

358 anti-predator behavior for sculpin, which take cover when under predator threat and sit

359 motionless under shelter (Shi et al. 2017). Both of these behaviors are supported by the

360 low distance travelled by sculpin when exhibiting this movement type. Thus, MT 1 could 
361 be associated with feeding and/or hiding, and further finer scale studies are required to

362 distinguish between the two for Shorthorn Sculpin.

363 We identified MT 2 as directional in-transit behavior, which is believed to be

364 associated with general dispersal, movement through inhospitable areas, movement

365 between prey patches and/or extra-home-range exploration due to the relatively large

366 ROM and distance travelled. McLean et al. (2014) identified a similar pattern of

367 movement for Atlantic Sturgeon (Acipenser oxyrinchus), which the authors described as

368 straight-line rapid movement with large mean distance between relocations, and

369 attributed to dispersal and movement between patches. This type of movement has been

370 observed for terrestrial species as well. Zollner \& Lima (1999) described it in their

371 simulation based on small forest mammals as related to extensive search of food patches,

372 where straight-line travel is utilized to minimize effort, but also, as a movement related to

373 greater risk, such as moving through areas with higher risk of mortality. Additionally,

374 Frafjord \& Prestrud (1992) linked this type of movement to extra home-range exploration

375 and roaming in Arctic Foxes (Alopex lagopus) in Svalbard, Norway.

376 Movement type 3 was identified as foraging, characteristic of movement between

377 food patches within the home range, due to its medium tortuosity and irregular movement

378 trajectory, resembling food search behavior. Coughlin et al. (1992) found swimming

379 paths for clownfish larvae (Amphiprion perideraion) were intermediate in complexity

380 when individuals were looking for food. McLean et al. (2014) attributed erratic

381 movements of Atlantic sturgeon to be associated with searching for food between

382 patches. A similar movement type has been observed for terrestrial species by Brown et 
383 al. (2017), who reported intermediate length of movements and turning angles when

384 butterflies were in low food quality habitats.

385 In 2013, in-transit movements by Shorthorn Sculpin decreased significantly when

386 vessels were present/anchored in the bay (VP) compared to when vessels were absent

387 (VA). Extra home range exploration, i.e. in-transit movement, is important for individuals

388 for updating the cognitive map of their home range as that information increases fitness

389 and survival, through, for example, mapping of food resources (Spencer 2012). This

390 indicates that sculpin were likely affected by the presence of vessels in the bay and

391 reduced their extra home-range exploration in response. However, interpretation here

392 needs to be made with caution, because in 2012 in-transit movement types showed no

393 statistical difference between VA and VP. Additionally, we saw a negative correlation of

394 in-transit movements for 2013 with photoperiod, but this correlation again was not

395 observed for any other years. Moore \& Moore (1974) found that Shorthorn Sculpin had

396 restricted visual capacity during ice cover and, thus, changed their food search behavior.

397 This suggests that at $24 \mathrm{~h}$ photoperiod sculpin have good visibility reducing the pressure

398 to search for food. However, with diminishing light conditions sculpin may spend more

399 time travelling between patches. A decrease in in-transit movements in 2013 may

400 therefore be linked to increased prey availability; unfortunately prey abundance data are

401 not available to test this idea, and any influences by vessels' presence cannot be

402 completely excluded as a cause at this point (see discussion in paragraphs below).

403 Therefore, our results regarding vessel presence influences on sculpin in-transit

404 movements are somewhat inconclusive, and we recommend further study. 
405 We also suggest that sculpin were aware of the presence of anchored vessels in 406 the bay, likely perceive it as a threat, and thus decrease exploratory behavior and the use 407 of their extended home range. Minimum convex polygon (MCP) represents the extent of 408 the area utilized by species in a habitat, which in our study was interpreted as extended 409 home range, or areas that an individual explores outside of its immediate home range.

410 The observed decrease of MCP in all years when vessels were present but not moving 411 implies reduced extra-home-range exploration when vessels are present in the bay. The

412 significant decrease of in-transit movements in 2013 and the overall movement type

413 proportions changing between VA and VP provide further evidence to support this. These

414 results are in agreement with disturbance studies on other species. For example, dolphins

415 (Tursiops aduncus) changed their overall behavioral patterns in response to boats (Pérez-

416 Jorge et al. 2017), while herring (Clupea harengus) exhibited vessel avoidance behavior

417 (Vabø et al. 2002). Similarly for terrestrial species, leopards (Panthera pardus) reduced

418 their overall activity, and rhinoceros (Diceros bicornis) and spider monkeys (Ateles spp.)

419 relocated and/ or reduced their home ranges to avoid human settlements and

420 anthropogenically disturbed areas, respectively (Ngoprasert et al. 2017; Odendaal-

421 Holmes et al. 2014; Asensio et al. 2017).

422 While Sculpin VP core home ranges (50\%) were still located within VA's larger

$423(95 \%)$ home range boundaries, there was low overlap of VP with VA core home ranges

$424(50 \%)$. We suggest that there is a shift of the core's locations during VP. Similar results

425 were observed for spider monkeys, which minimize the use of a particular part of their

426 home range based on the degree of habitat disparity due to disturbance (Asensio et al.

427 2017). Anchored vessels run generators to supply electricity for everyday use and thus, 
428 produce noise. This noise along with the associated particle pressure are likely perceived

429 as predator threat, and cause habitat disparity in our study; when under threat sculpin are

430 known to utilize shelter (Moring 2001). The seabed of Resolute Bay has patchily

431 distributed vegetation cover, and a shift in the core when vessels were present likely

432 indicates relocation of the individual to an area within their home range with more

433 vegetation cover, where shelter is easily accessible. Similar behavior has been observed

434 for Brown Trout (Salmo trutta) which had increased preference for territories with cover

435 after simulated predator attack (Johnsson et al. 2004), and for Three-Spined Stickleback

436 (Gasterosteus aculeatus), which prefer to build their nests near vegetation as shelter from

437 predators (Huntingford \& Coyle 2007). The observed shift in the location of the core

438 home ranges provides further evidence of vessel presence influences on sculpin.

439 There were fewer detections in 2014 than 2012 and 2013, and quantified MTs are

440 likely compromised, with only four bursts observed for VP. There are two likely

441 explanations for the observed low number of detections in 2014:1) less coverage of bay

442 due to fewer receivers used in array (28 receivers in 2014 versus 44 in 2012 and 2013;

443 detections range varied between 10 to $130 \mathrm{~m}$ (Kessel et al. 2015)), and 2) smaller tagged

444 sculpin in 2014 left the area due to size segregation associated with cannibalism by larger

445 and older conspecifics (Pfister 2003; Petty \& Rossman 2007). Sculpin are territorial

446 (Petty \& Rossman 2007) and as such are very individualistic, i.e. they do not form

447 schools or occur in groups. They are also known for cannibalism (Pfister 2003; Landry

448 JJ, Fisk, AT, Yurkowski, DJ, Hussey, NE, Dick, T, Crawford, RE, and Kessel ST. In

449 press) and size-dependent intraspecific competitive interaction, thus smaller sculpin

450 avoid close encounters with larger individuals (Petty \& Rossman 2007). Since sculpin 
451 tagged in 2014 were significantly smaller, they may have avoided larger conspecifics and

452 may have moved out of the array's effective range. Due to this, movement types for 2014

453 were not considered in the results and conclusions. Home range data were included in the

454 spatial analysis because there were sufficient detections per individual to extract these

455 and calculate overlaps. Important to note here is that there were fewer individuals

456 included in the analysis of 2014 home ranges compared to other years (see Table 2).

457 The observed inconsistencies between years for the quantified MTs may be due

458 to: 1) an overall small sampling size for sculpin, and 2) environmental variation between

459 years. In 2012, 22 individuals were tagged, but only 17 individuals were used for analysis

460 for VA and VP (Table 2), while in 2013 we tagged 14 fish but were able to use 11 for VA

461 and VP. Although all tagged individuals for both years were detected, some individuals

462 appear to have left the system for the period of our study, resulting in insufficient number

463 of detections for the statistical analysis. Environmental factors also showed variation in

464 the months of August and September between 2012 and 2013. For example, average

465 monthly air temperature for the two months of interest was $0.9^{\circ} \mathrm{C}$ in 2012 and $-2.25^{\circ} \mathrm{C}$

466 in 2013; and total precipitation also varied between years, $28.9 \mathrm{~mm}$ in 2012 compared to

$4679.05 \mathrm{~mm}$ in 2013 (Environment and Climate Change Canada 2017). Also, differences

468 between 2012 and 2013 were seen in salinity means ( 32 and 29, respectively), water

469 temperature $\left(-0.33^{\circ} \mathrm{C}\right.$ and $\left.-1.1^{\circ} \mathrm{C}\right)$ and dissolved oxygen $(81.7$ and 72.8$)$. Thus,

470 environmental variation along with small sampling size may partly explain the inter-

471 annual variation observed in our results for MTs between years.

472 Taken together, the results of this study suggest Shorthorn Sculpin are influenced

473 by vessel activity in Resolute Bay. We observed a change in the proportions of different 
474 movement types and behavior and in the spatial area use by individual fish during vessel

475 presence. While changes in movement types associated with vessel activity did not show

476 consistency throughout years, spatial area use changes were consistent and the overall

477 results clearly support further study on the impact of increasing vessel traffic and

478 associated activity on fish in the arctic and other regions. It is likely that the observed

479 inter annual variation in MTs was a result of a combination of changes in study design

480 among years and environmental differences. In addition, more research is required to

481 establish the mechanisms by which vessels affect sculpin, and the noise and particle

482 pressure tolerance levels of this species. The implications these may have for sculpin are

483 at this point unclear and additional examination is required pertaining to prey, and any

484 effects vessels may have on sculpin's feeding and foraging behaviors under varying prey

485 availability. Shorthorn Sculpin are an integral part of the Arctic food web, and are

486 believed to be a good indicator of changes in the Arctic marine ecosystem (Dick et al.

487 2009). Our study provides the first assessment of vessel influences on the fine scale

488 movements and home ranges for this species in the Arctic. As such, it provides a baseline

489 to which future studies on general vessel activity influences in the high Arctic, sculpin,

490 and sculpin behavior and home ranges can be compared.

492 Acknowledgements

493 This project was funded by the Ocean Tracking Network through the Canada Foundation

494 for Innovation and the Natural Sciences and Engineering and Research Council of

495 Canada and Polar Continental Shelf Research Project to ATF, and the Northern Studies

496 Training Program scholarship to SVI. Many thanks are extended to the community of 
497 Resolute Bay, Rick Crawford and Meagan McCloskey for their assistance with 498 fieldwork. 


\section{References}

500 Anon, 2013. Resolute Bay. Government of Nunavut.

501 Asensio, N. et al., 2017. The effect of roads on spider monkeys' home range and mobility

502 in a heterogeneous regenerating forest. Biotropica, 49(4), pp.546-554.

503 Breton-Honeyman, K. et al., 2016. Inuit Knowledge of beluga whale (Delphinapterus

504 leucas) foraging ecology in Nunavik (Arctic Quebec), Canada. Canadian Journal of $505 \quad$ Zoology, 94, pp.713-726.

506 Brown, L.M. et al., 2017. Using animal movement behavior to categorize land cover and

507 predict consequences for connectivity and patch residence times. Landscape

$508 \quad$ Ecology, 32(8), pp.1657-1670.

509 Calenge, C., 2006. The package adehabitat for the R software: a tool for the analysis of

510 space and habitat use by animals. Ecological Modeling, 197, pp.516-519.

511 Calenge, C., Dray, S. \& Royer-Carenzi, M., 2009. The concept of animals' trajectories

512 from a data analysis perspective. Ecological Informatics, 4, pp.34-41.

513 Comiso, J.C. et al., 2008. Accelerated decline in the Arctic Sea ice cover. Geophysical

$514 \quad$ Research Letters, 35(1), p.

515 Cooke, S.J. et al., 2013. Tracking animals in freshwater with electronic tags: past, present

516 and future. Animal Biotelemetry, 1(5), pp.1-19.

517 Coughlin, D.J., Strickler, J.R. \& Sanderson, B., 1992. Swimming and search behaviour in

518 clownfish, Amphiprion perideraion, larvae. Animal Behaviour, 44(PART 3),

$519 \quad$ pp.427-440.

520 Cressey, D., 2011. Open water: As the ice melts, fresh obstacles confront Arctic

521 researchers. Nature, 478, pp.174-177. 
522 Dawson, J., Johnston, M.E. \& Stewart, E.J., 2014. Governance of Arctic expedition

523 cruise ships in a time of rapid environmental and economic change. Ocean and

$524 \quad$ Coastal Management, 89, pp.88-99.

525 Dick, T., Chambers, C. \& Gallagher, C.P., 2009. Parasites, diet and stable isotopes of

526 shorthorn sculpin (Myoxocephalus scorpius) from Frobisher Bay, Canada. Parasite,

$527 \quad$ 16, pp.297-304.

528 Divoky, G. \& Tremblay, Y., 2013. Shifting Prey in a Melting Ocean: Seabirds Reveal

529 Annual and Seasonal Changes in Arctic Nearshore Fish, Available at:

$530 \quad$ https://seagrant.uaf.edu/conferences/2013/wakefield-arctic-

531 ecosystems/presentations/divoky-seabirds-fish.pdf.

532 Environment and Climate Change Canada, 2017. Monthly Data Report-Climate-

533 Environment and Climate Change Canada. Government of Canada. Available at:

$534 \quad$ climate.weather.gc.ca [Accessed January 17, 2017].

535 Eriksson, B.K. et al., 2004. Effects of boating activities on aquatic vegetation in the

536 Stockholm archipelago, Baltic Sea. Estuarine, Coastal and Shelf Science, 61, $537 \quad$ pp.339-349.

538 Espinoza, M. et al., 2011. Testing a new acoustic telemetry technique to quantify long-

539 term, fine-scale movements of aquatic animals. Fisheries Research, 108(2-3),

$540 \quad$ pp.364-371.

541 Fieberg, J. \& Kochanny, C.O., 2005. Quanitfying home-range overlap: the importance of

542 the utilization distribution. Journal of Wildlife Management, 69(4), p.1346.

543 Fisk, A.T. et al., 2002. Using anthropogenic contaminants and stable isotopes to assess

544 the feeding ecology of greenland sharks. Ecology, (83), pp.2162-2172. 
545 Frafjord, K. \& Prestrud, P., 1992. Home range and movements of Arctic foxes (Alopex

546 lagopus) in Svalbard. Polar Biology, 12, pp.519-526.

547 Fraley, C. \& Raftery, A.E., 1999. MCLUST: Software for Model-Based Cluster Analysis.

$548 \quad$ Journal of Classification, 16, pp.297-306.

549 Grans, A. et al., 2013. Effects of acute temperature changes on gut physiology in two

$550 \quad$ species of sculpin from the west coast of Greenland. Polar Biology, (36), pp.775-

$551 \quad 785$.

552 Hauser, S. et al., 2014. Population-specific home ranges and migration timing of Pacific

553 Arctic beluga whales (Delphinapterus leucas). Polar Biology, 37, pp.1171-1183.

554 Heide-Jørgensen, M.P. et al., 2003. The migratory behaviour of narwhals (Monodon

555 monoceros). Canadian Journal of Zoology, 81, pp.1298-1305.

556 Heupel, M.R. et al., 2012. Consistent movement traits indicative of innate behavior in

557 neonate sharks. Journal of Experimental Marine Biology and Ecology, 432-433,

558 pp.131-137. Available at: http://dx.doi.org/10.1016/j.jembe.2012.07.013.

559 Holles, S.H. et al., 2013. Boat noise disrupts orientation behaviour $\mathrm{n}$ a coral reef fish.

560 Marine Ecology Progress Series, 485, pp.295-300.

561 Huntingford, F.A. \& Coyle, S., 2007. Antipredator Defences in Sticklebacks: Trade-Offs,

562 Risk Sensitivity and Behavioural Syndromes. In S. Ostlund-Nilsson, I. Mayer, \& F.

563 A. Huntingford, eds. Biology of the Three-Spined Stickleback. Boca Raton, FL: CRC

$564 \quad$ Press, pp. 127-156.

565 Hussey, N.E. et al., 2015. Aquatic animal telemetry: A panoramic window into the

566 underwater world. Science (New York, N.Y.), 348(6240), p.1255642-. Available at:

567 http://www.sciencemag.org/content/348/6240/1255642.full?utm_campaign=email- 
568 sci-toc\&utm_src=email.

569 Johnsson, J.I., Rydeborg, A. \& Sundstrom, L.F., 2004. Predation risk and the territory

570 value of cover: an experimental study. Behavioral Ecology and Sociobiology, 56(4),

$571 \quad$ pp.388-392.

572 Kasumyan, A.O., 1999. Olfaction and taste senses in sturgeon behaviour. Journal of

573 Applied Ichthyology-Zeitschrift Fur Angewandte Ichthyologie, 15(4-5), pp.228-232.

574 Kessel, S.T. et al., 2015. Distinct patterns of Arctic cod (Boreogadus saida) presence and

575 absence in a shallow high Arctic embayment, revealed across open-water and ice-

576 covered periods through acoustic telemetry. Polar Biology, pp.1-12. Available at:

577 http://link.springer.com/10.1007/s00300-015-1723-y.

578 Kessel, S.T. et al., 2017. First documented large-scale horizontal movements of

579 individual Arctic cod (Boreogadus saida). Canadian Journal of Fisheries and

580 Aquatic Sciences, 296(January), pp.292-296.

581 Kortsch, S. et al., 2015. Climate change alters the structure of arctic marine food webs

582 due to poleward shifts of boreal generalists. Proceedings of the Royal Society B of

583 the Royal Society B, (282).

584 Lowry, L.F., Frost, K.J. \& Burns, J.J., 1980. Variability in the diet of Ringed seals, Phoca

585 hispida, in Alaska. Canadian Journal of Fisheries and Aquatic Sciences, 37 ,

$586 \quad$ pp.2254-2261.

587 McLean, M.F. et al., 2014. Diversity of behavioural patterns displayed by a summer

588 feeding aggregation of Atlantic sturgeon in the intertidal region of Minas Basin, Bay

589 of Fundy, Canada. Marine Ecology Progress Series, 496, pp.59-69.

590 Moore, I.A. \& Moore, J.W., 1974. Food of Shorthorn Sculpin, Myoxocephalus scorpius, 
591

592

593 Moring, J.R., 2001. Appearance and possible homing of two species of sculpins in Maine 594 tidepools. Northeastern Naturalist, 8(2), pp.207-218.

595 Ngoprasert, D., Lynam, A.J. \& Gale, G.A., 2017. Effects of temporary closure of a

596 national park on leopard movement and behaviour in tropical Asia. Mammalian

597 Biology, 82, pp.65-73. Available at:

598 http://dx.doi.org/10.1016/j.mambio.2016.11.004.

599 Nowacek, D.P. et al., 2007. Responses of cetaceans to anthropogenic noise. Mammal $600 \quad$ Review, 37(2), pp.81-115.

601 Odendaal-Holmes, K., Marshal, J.P. \& Parrini, F., 2014. Disturbance and habitat factors

602 in a small reserve: space use by establishing black rhinoceros (Diceros bicornis).

603 South African Journal of Wildlife Research, 44, pp.148-160.

604 Pérez-Jorge, S. et al., 2017. Deep-Sea Research II Estimating the cumulative effects of

605 the nature-based tourism in a coastal dolphin population from southern Kenya.

606 Deep-Sea Research II, 140, pp.278-289. Available at:

$607 \quad$ http://dx.doi.org/10.1016/j.dsr2.2016.08.011.

608 Petty, J.T. \& Rossman, G.D., 2007. Size-Dependent Territoriality of Mottled Sculpin in a

609 Southern Appalachian Stream. Transactions of the American Fisheries Society, $610 \quad$ (136), pp.1750-1761.

611 Pfister, C.A., 2003. Some consequences of size variability in juvenile prickly sculpin, 612 Cottus asper. Environmental Biology of Fishes, pp.383-390.

613 Richardson, M. et al., 2016. Reconciled climate response estimates from climate models 
614 and the energy budget of Earth. Nature Climate Change, pp.1-22. Available at:

615 http://www.nature.com/doifinder/10.1038/nclimate3066.

616 Russell, I.C. et al., 1998. The migratory behaviour of juvenile and adult salmonids in 617 relation to an estuarine barrage. Hydrobiologia, (165555), pp.321-333.

618 Sandström, A. et al., 2005. Boating and navigation activities influence the recruitment of 619 fish in a Baltic Sea archipelago area. The Journal of the Human Environment, 34(2), $620 \quad$ pp.125-130.

621 Seth, H. et al., 2013. Metabolic Scope and Interspecific Competition in Sculpins of 622 Greenland Are Influenced by Increased Temperatures Due to Climate Change. PLoS $623 \quad O N E, 8(5)$.

624 Shi, X. et al., 2017. The angular position of a refuge affects escape responses in staghorn 625 sculpin Leptocottus armatus. Journal of Fish Biology, pp.2434-2442.

626 Simpson, S.D. et al., 2016. Anthropogenic noise increases fish mortality by predation.

$627 \quad$ Nature communications, 7, p.10544. Available at:

628 http://www.pubmedcentral.nih.gov/articlerender.fcgi?artid=4748250\&tool=pmcentr 629 ez\&rendertype=abstract.

630 Slabbekoorn, H. et al., 2010. A noisy spring: The impact of globally rising underwater 631 sound levels on fish. Trends in Ecology and Evolution, 25(7), pp.419-427.

632 Smith, F., 2013. Understanding HPE in the VEMCO Positioning System ( VPS ). Vemco, 633 pp.1-31. Available at: http://vemco.com/wp634 content/uploads/2013/09/understanding-hpe-vps.pdf.

635 Spencer, W.D., 2012. Home ranges and the value of spatial information. Journal of 636 Mammalogy, 93(4), pp.929-947. 
637 Standing Senate Committee on Fisheries and Oceans, 2009. Controlling Canada's Arctic 638 Waters: Role of the Canadian Coast Guard,

639 Steffen Thorsen, 2014. Sunrise and sunset times in Resolute Bay. timeanddate.com.

640 Available at: https://www.timeanddate.com/sun/canada/resolute [Accessed January $64122,2017]$.

642 Turchin, P., 1998. Quantitative Analysis of Movement: measuring and modeling 643 population redistribution in plants and animals, Sunderland, MA: Sinauer $644 \quad$ Associates.

645 US Energy Information Administration, 2012. Arctic oil and natural gas resources. US 646 Energy Information Administration. Available at:

647 https://www.eia.gov/todayinenergy/detail.php?id=4650 [Accessed July 2, 2016].

648 Vabø, R., Olsen, K. \& Huse, I., 2002. The effect of vessel avoidance of wintering 649 Norwegian spring spawning herring. Fisheries Research, 58(1), pp.59-77.

650 Vaudo, J.J. \& Lowe, C.G., 2006. Movement patterns of the round stingray Urobatis 651 halleri (Cooper) near a thermal outfall. Journal of Fish Biology, 68(6), pp.1756$652 \quad 1766$.

653 Weather Canada, 2015. Hourly Data Report [data set]. Environment and Climate Change $654 \quad$ Canada. Available at:

655 http://climate.weather.gc.ca/historical_data/search_historic_data_e.html [Accessed $656 \quad$ November 1, 2015].

657 Wysocki, L.E., Dittami, J.P. \& Ladich, F., 2006. Ship noise and cortisol secretion in 658 European freshwater fishes. Biological Conservation, 128(4), pp.501-508.

659 Zollner, P.A. \& Lima, S.L., 1999. Search strategies for landscape-level interpatch 
660 movements. Ecology, 80(3), pp.1019-1030.

661 
662 Table 1: Total length, mass and condition index (mean \pm 1 standard error) for all tagged

663 Shorthorn Sculpin in Resolute Bay, Nunavut. Letters indicate significant differences

664 between years (t-test, $\mathrm{p}<0.05)$.

\begin{tabular}{|c|c|c|c|c|}
\hline Year & $\boldsymbol{n}$ & Total length (cm) & Mass (g) & Condition index \\
\hline 2012 & 22 & $28.1 \pm 0.6^{\mathrm{A}}$ & $319.4 \pm 20.3^{\mathrm{A}}$ & $14.1 \pm 0.4$ \\
\hline 2013 & 12 & $28.9 \pm 1.3^{\mathrm{A}}$ & $359.4 \pm 55.2^{\mathrm{A}}$ & $13.9 \pm 0.4$ \\
\hline 2014 & 26 & $23.2 \pm 0.5^{\mathrm{B}}$ & $174.8 \pm 13.8^{\mathrm{B}}$ & $13.5 \pm 0.2$ \\
\hline
\end{tabular}

665 
666 Table 2: Number of unique Shorthorn Sculpin individuals (detected and used for further

667 analysis), and number of total and used detections in spatial analysis from acoustic

668 telemetry study in Resolute Bay, Nunavut.

\begin{tabular}{|c|c|c|c|}
\hline \multirow{2}{*}{$\mathbf{2 0 1 2}$} & Vessel State & $\begin{array}{c}\text { \# of unique IDs } \\
\text { detected } \\
\text { (\# of IDs used in } \\
\text { analysis) }\end{array}$ & $\begin{array}{c}\text { Total \# of } \\
\text { detections } \\
\text { (Total used in } \\
\text { analysis) }\end{array}$ \\
\cline { 2 - 4 } & Vessels Absent (VA) & $22(17)$ & $12,803(12,642)$ \\
\cline { 2 - 4 } & Vessels Present (VP) & $18(17)$ & $3,716(3,679)$ \\
\hline \multirow{3}{*}{2013} & Vessels Absent (VA) & $13(7)$ & $54(48)$ \\
\cline { 2 - 4 } & Vessels Present (VP) & $14(11)$ & $14,282(13,759)$ \\
\cline { 2 - 4 } & Vessels Moving in bay (VM) & $13(11)$ & $2,558(2,553)$ \\
\hline \multirow{2}{*}{2014} & Vessels Absent (VA) & $14(4)$ & $36(22)$ \\
\cline { 2 - 4 } & Vessels Present (VP) & $8(4)$ & $4,040(681)$ \\
\cline { 2 - 4 } & Vessels Moving in bay (VM) & $2(2)$ & 21 \\
\hline
\end{tabular}

669 
670 Table 3: Frequencies of movement types (MT) of Shorthorn Sculpin in Resolute Bay,

671 Nunavut, used to calculate for each year MT proportions per vessel variable. Vessel

672 variables are as follows: VA - vessels absent from the bay; VP - vessels present in the

673 bay; and VM - vessels moving (entering or exiting the bay).

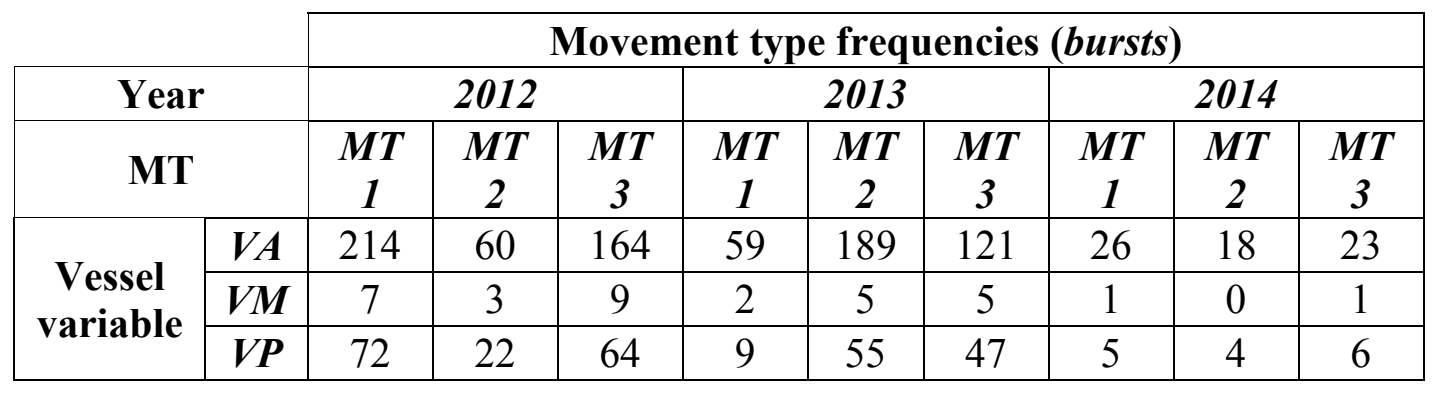

674

675 
676 Fig. 1: Location of Resolute Bay, Nunavut, Canada. The inset depicts the bathymetry of

677 the bay (depth is shown in meters) and the features surrounding it. Thin black lines

678 denote the eastern and western shipping lanes and the anchoring locations are denoted

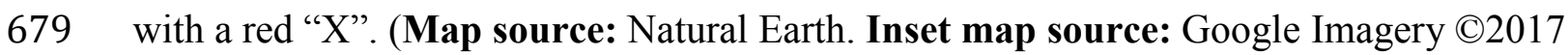

680 TerraMetrics)

681 Fig. 2: Locations of acoustic telemetry receivers in Resolute Bay, Nunavut by year.

682 Numbers of receivers in each array are 44 for 2012 and 2013, and 28 for 2014.

683 Fig. 3: Examples of Shorthorn Sculpin movement descriptive parameters versus

684 movement type with respective significance values (Kruskall-Wallis rank sum test) from

685 acoustic telemetry study in Resolute Bay, Nunavut. Significant p-values are denoted with

686 star symbols. Only significant descriptive parameters were used to define the movement

687 types $(\mathrm{ROM}=$ rate of movement, $\mathrm{SD}=$ standard deviation $)$.

688 Fig. 4: Samples of Shorthorn Sculpin movement types from Resolute Bay, Nunavut (note

689 differences in scales). Circles denote detection locations with green identifying the

690 starting point of the movement and black line denotes the movement path. An example of

691 MT 1 associated with feeding/hiding is shown for individual 6008. This particular burst

692 had a mean rate of movement (ROM) of $0.003 \mathrm{~m} / \mathrm{s}$, mean acceleration of 0.06 , and 0.016

693 linearity ratio (shown are all 246 positions detected over a period of 30 hours). Example

694 of MT 2 associated with in-transit movement is shown for individual with tag number

695 6018. Mean ROM for this behavior was $0.165 \mathrm{~m} / \mathrm{s}$, with mean acceleration of 1.16 , and

6960.88 linearity ratio (shown are all 20 positions detected over a period of 3 hours).

697 Example of MT 3 associated with foraging is from individual 6018 and had mean ROM 
698 of $0.021 \mathrm{~m} / \mathrm{s}, 0.25$ mean acceleration, and 0.48 linearity ratio (shown are all 158 positions

699 detected over a period of 21.5 hours).

700 Fig. 5: Mean proportions of movement types for Shorthorn Sculpin per vessel variable in

701 Resolute Bay, Nunavut. VA denotes periods with vessels absent from the bay, VP is for

702 periods with vessels present and VM for periods with vessels moving in the bay.

703 Fig. 6: Linear regression relationships of each movement type (MT) versus photoperiod

704 for 2013 for Shorthorn Sculpin, Resolute Bay, Nunavut.

705 Fig. 7: Mapped Shorthorn Sculpin home ranges for three individuals from Resolute Bay,

706 Nunavut. Dark and light pink denote 50\% and 95\% KUD for VA, respectively, dark and

707 light blue denote these for VP, and yellow and light green denote these for VM home

708 ranges.

709 Fig. 8: Mean minimum convex polygon (MCP), 50 and 95\% home range area sizes for

710 Shorthorn Sculpin individuals from Resolute Bay, Nunavut, are plotted against vessel

711 variables. In 2012, MCP area sizes for vessel presence (VP) and movement (VM)

712 decreased when compared to periods with no vessels (VA; $p$-value $=0.002$, and $<0.001$,

713 respectively; Kruskal-Wallis rank sum test). In 2013, MCP decreased significantly during

714 VP and VM ( $p=0.028$ and 0.01 , respectively; Kruskal-Wallis rank sum test). Area sizes

715 for $50 \%$ and $95 \%$ home ranges also decreased significantly for VM as compared to VA

$716(\mathrm{p}=0.016$ for both). In 2014, no significant differences were found in any of the area

717 sizes. Numbers of individuals used for the analysis were as follows: VA $n=4, \mathrm{VP} n=4$,

718 and $\mathrm{VM} \mathrm{n}=2$. 


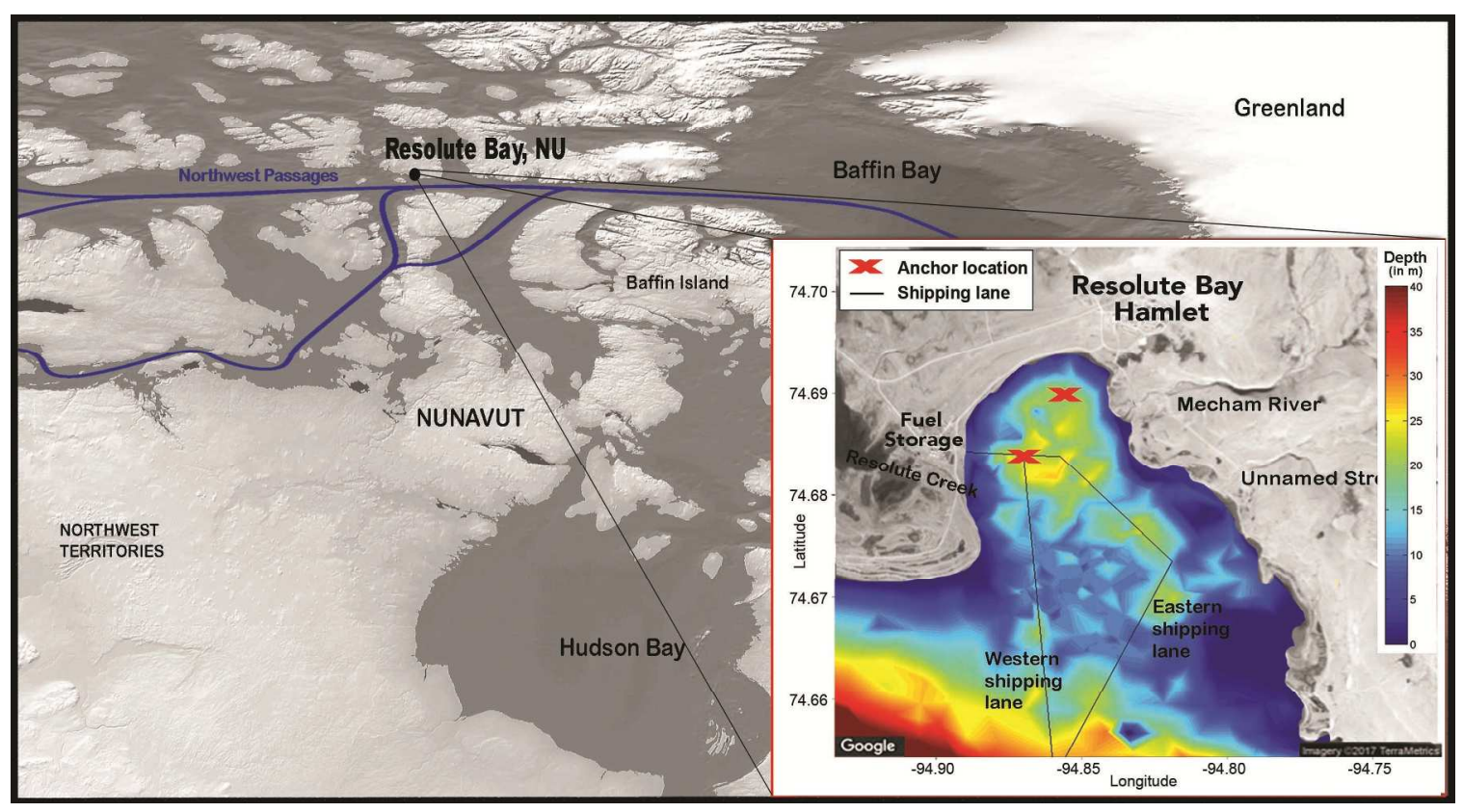

\section{$720 \quad$ Figure 1}



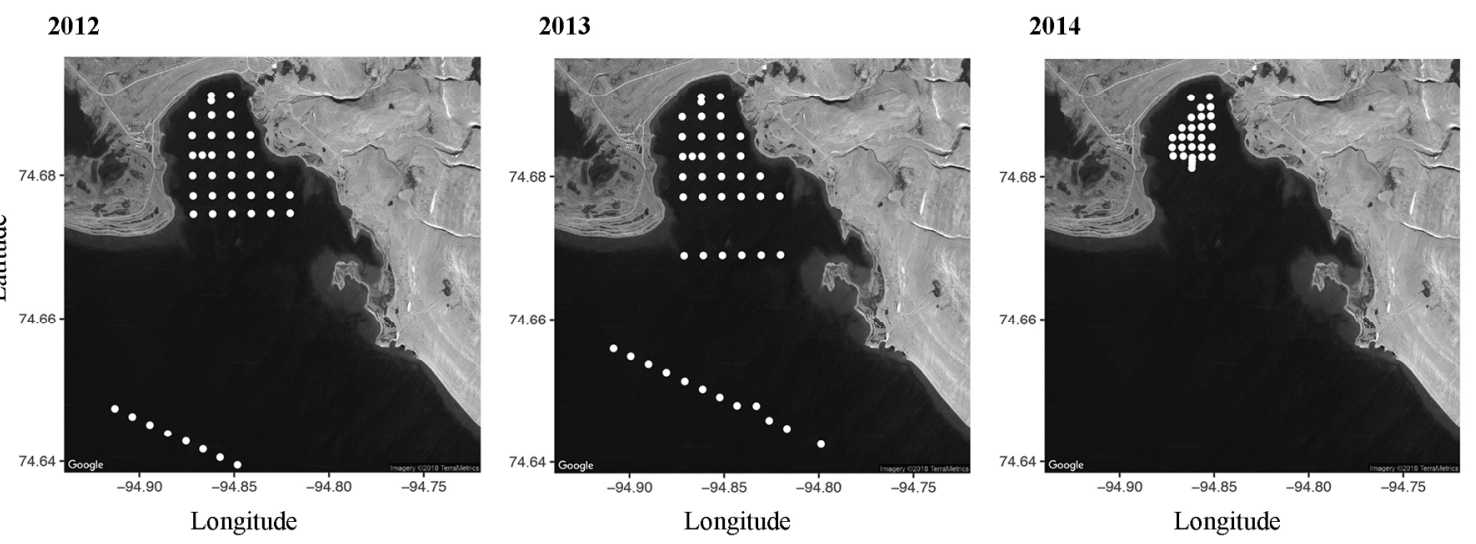

\section{$722 \quad$ Figure 2}


2012
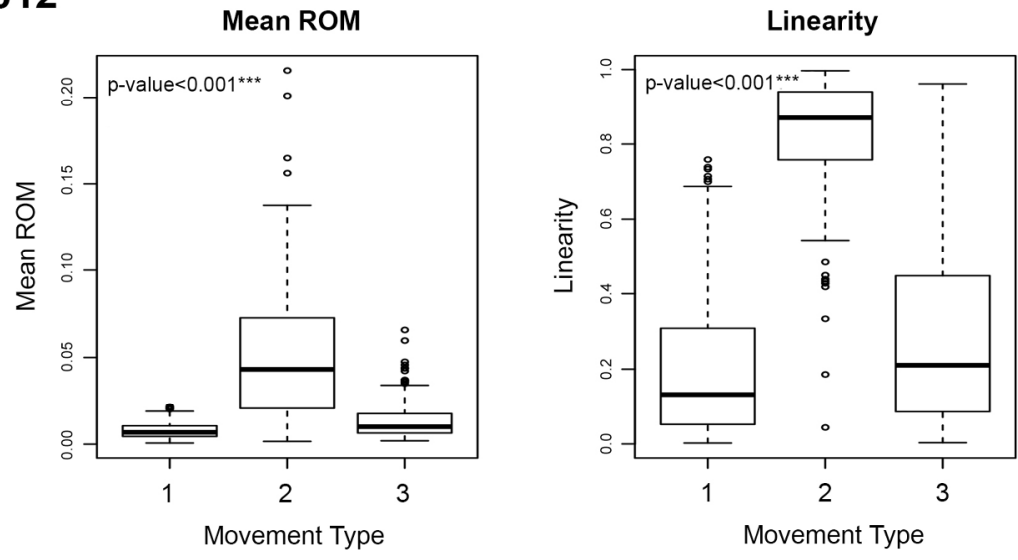

\section{3}
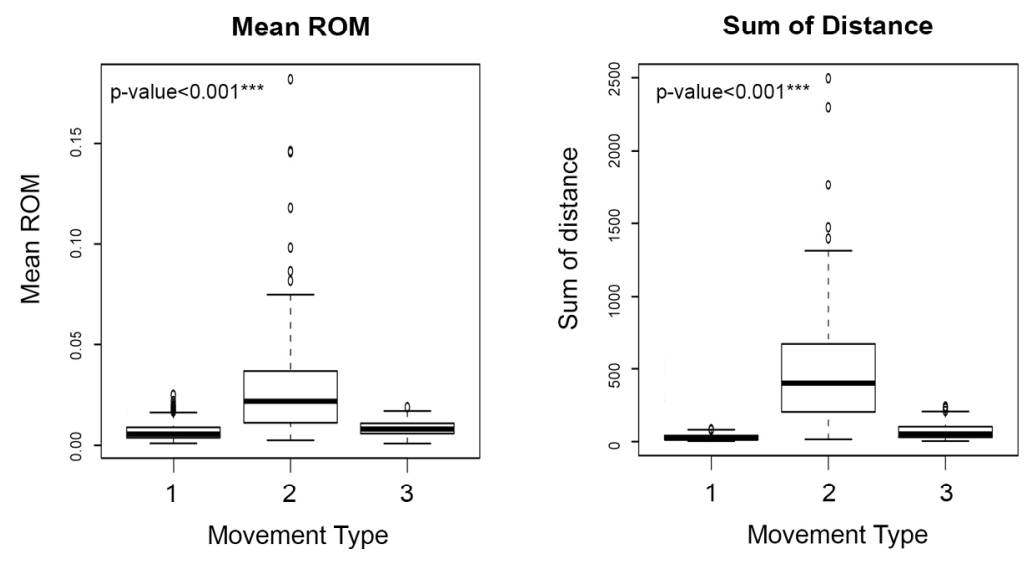

\section{4}
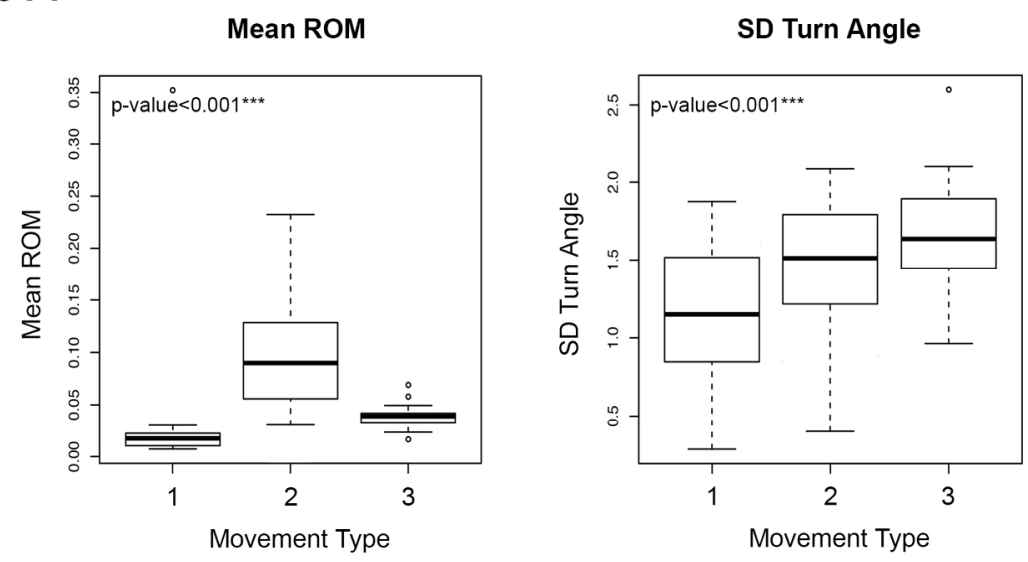

723

\section{$724 \quad$ Figure 3}



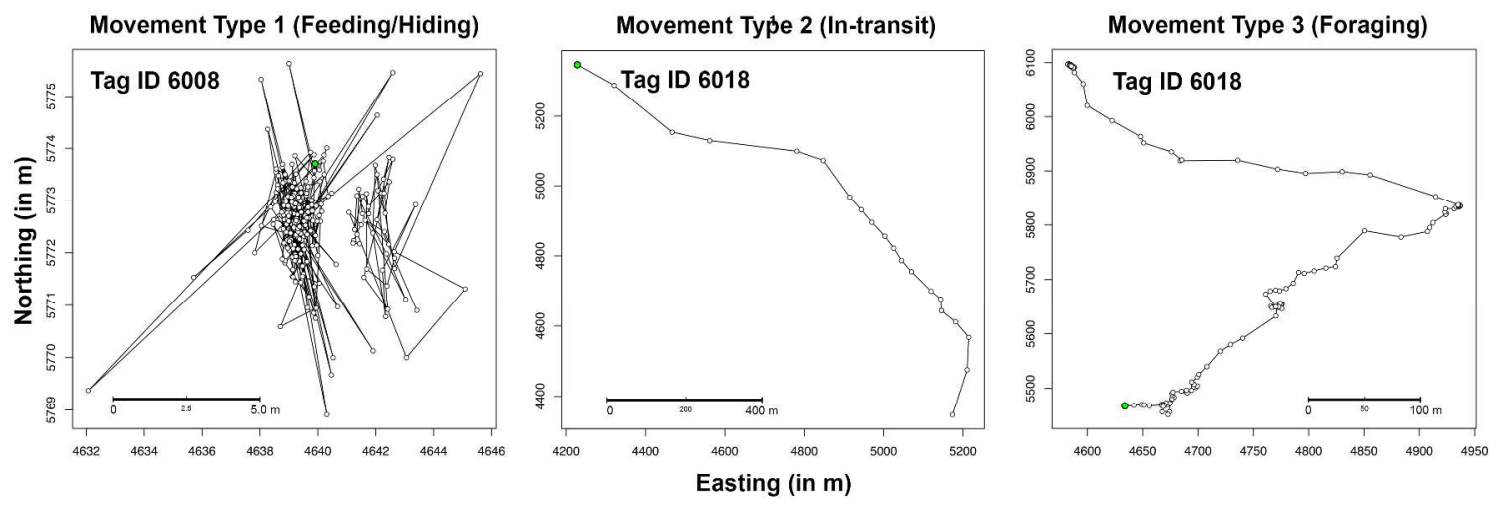

\section{$726 \quad$ Figure 4}



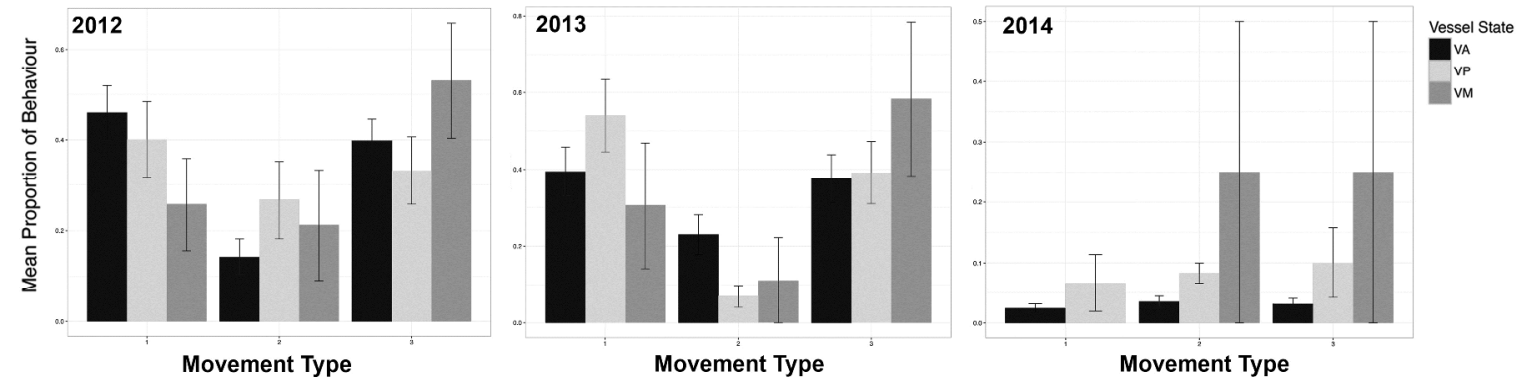

\section{$728 \quad$ Figure 5}




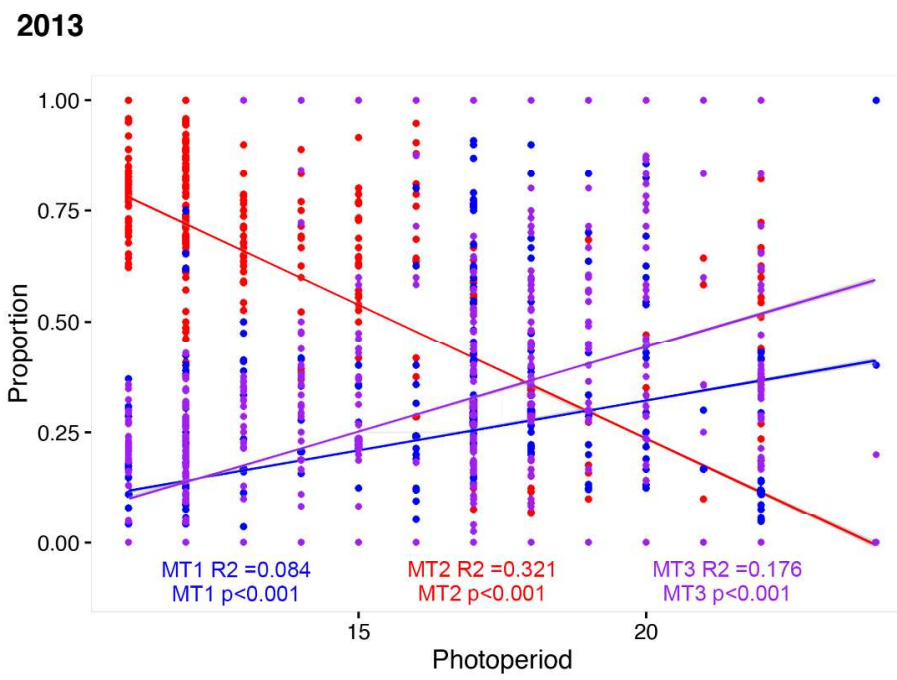

\section{$730 \quad$ Figure 6}




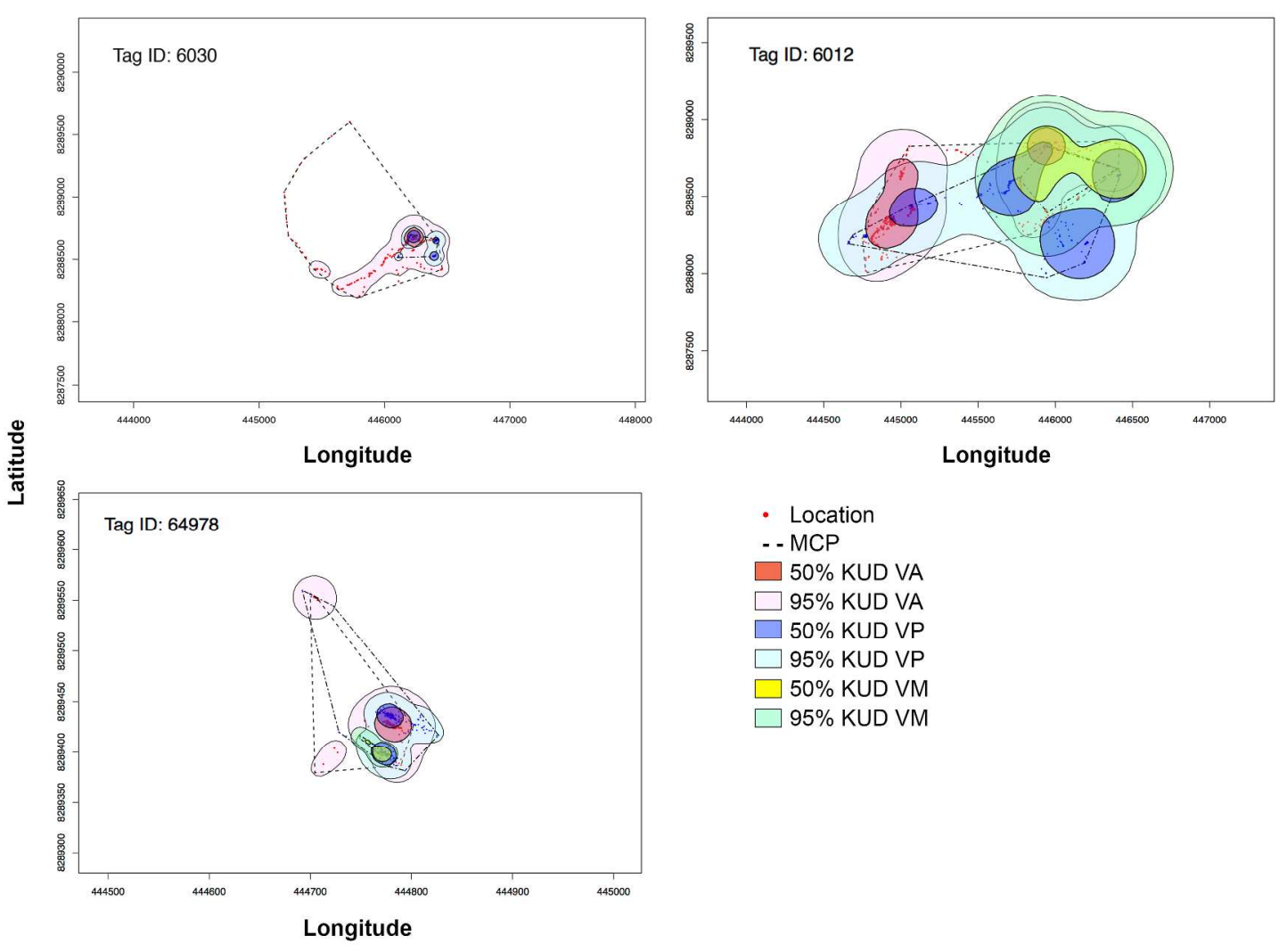

731

\section{$732 \quad$ Figure 7}


2012
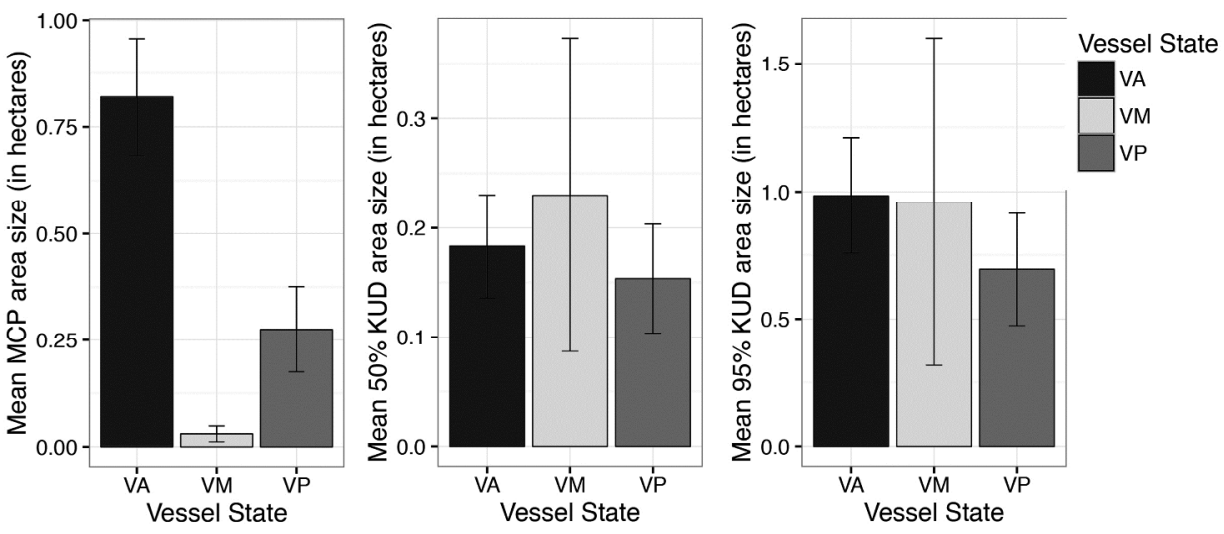

2013
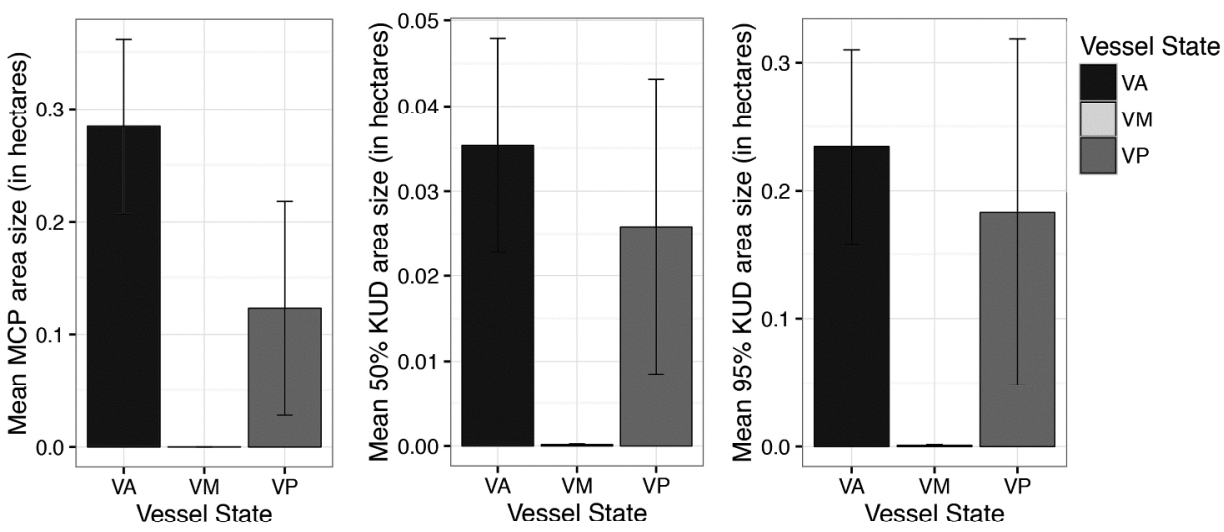

2014
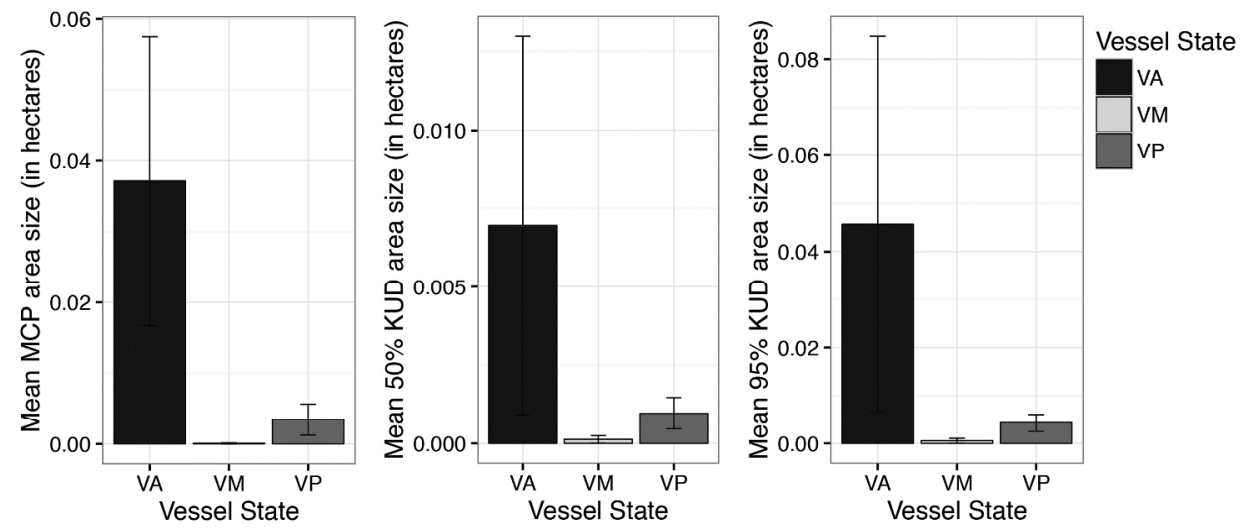

\section{$734 \quad$ Figure 8}

